Meta

Journal des traducteurs

Translators' Journal

\title{
La traduction dans la tradition arabe
}

\section{Taïeb Baccouche}

Volume 45, numéro 3, septembre 2000

La traduction dans le monde arabe

URI : https://id.erudit.org/iderudit/001936ar

DOI : https://doi.org/10.7202/001936ar

Aller au sommaire du numéro

Éditeur(s)

Les Presses de l'Université de Montréal

ISSN

0026-0452 (imprimé)

1492-1421 (numérique)

Découvrir la revue

Citer cet article

Baccouche, T. (2000). La traduction dans la tradition arabe. Meta, 45(3),

395-399. https://doi.org/10.7202/001936ar
Résumé de l'article

La traduction occupe une place de choix dans la pensée et la culture arabes. Cela se vérifie à travers les politiques menées dans ce domaine pendant les premières dynasties de l'Islam, la réflexion théorique millénaire sur ces questions et le rôle joué par les traducteurs dans le transfert des connaissances d'une culture à une autre (du grec et du persan vers l'arabe).La traduction continue à jouer le même rôle dans les politiques de développement dans les pays arabes mais sans permettre l'essor atteint par les arabes il y a plus de dix siècles. La raison semble être de nature structurelle. 


\title{
La traduction dans la tradition arabe
}

\author{
TAÏEB BACCOUCHE \\ Université de Tunis I, Tunis, Tunisie
}

\begin{abstract}
RÉSUMÉ
La traduction occupe une place de choix dans la pensée et la culture arabes. Cela se vérifie à travers les politiques menées dans ce domaine pendant les premières dynasties de l'Islam, la réflexion théorique millénaire sur ces questions et le rôle joué par les traducteurs dans le transfert des connaissances d'une culture à une autre (du grec et du persan vers l'arabe).

La traduction continue à jouer le même rôle dans les politiques de développement dans les pays arabes mais sans permettre l'essor atteint par les arabes il y a plus de dix siècles. La raison semble être de nature structurelle.
\end{abstract}

\section{ABSTRACT}

Translation holds an important place in Arabic thought and culture. This can be seen in the policies in effect in this field during the first dynasties of Islam, the thousand-year-old theoretical refection on these issues and the role played by translators in the transfer of knowledge from one culture to another (from Greek and Person into Arabic).

Translation still plays the same role in policies of development in Arab countries, but without bringing about the growth reached by the Arabs more than ten centuries ago. The reasons for this seem to be of a structural nature.

\section{MOTS-CLÉS/KEYWORDS}

tradition, traduction, arabe, culture, Islam

1) La traduction tient dans la pensée et la culture arabes une place de choix depuis l'aube de l'ère arabo-islamique qui couvre toute la période que les historiens modernes appellent le Moyen Âge, soit environ un millier d'années.

Cette activité, particulièrement intense, notamment aux viII ${ }^{\mathrm{e}}$ et $\mathrm{IX}^{\mathrm{e}}$ siècles ap. J.-C., a joué un rôle de premier plan dans la conservation des produits de la culture ancienne, notamment grecque, et dans le transfert de cette culture de l'Orient vers l'Occident, culture qui servira de base à la «Renaissance» de l'Europe, ou plus exactement, au développement de la civilisation planétaire moderne.

Une telle activité constituait en fait le développement spectaculaire d'une activité plus ancienne, pratiquée naturellement et spontanément pour faciliter les contacts et la communication entre les peuples et les États en temps de paix comme en temps de guerre.

Les nombreuses inscriptions bilingues et même quadrilingues de l'Antiquité en sont un témoignage éloquent dans tout le Moyen-Orient. C'est précisément grâce à de telles inscriptions que des écritures devenues inintelligibles ont été déchiffrées; l'exemple le plus célèbre étant l'hiéroglyphe des pharaons déchiffré par Champollion au début du $\mathrm{XIX}^{\mathrm{e}}$ siècle grâce à la traduction grecque. Sans cet admirable recours qu'est la traduction, d'autres écritures non déchiffrées, comme celle des Incas, sont restées lettre morte. 
2) «Adressez-vous aux gens dans l'idiome qu'ils comprennent», tel est l'un des plus célèbres dits du Prophète Mohammed, devenue formule courante. La tradition précise qu'il s'adressait aux délégations des tribus arabes venues puiser à la source le nouveau message divin, dans leur langue (= dialecte), et qu'il justifiait la diversité des lectures coraniques par le fait que le Coran lui a été révélé dans sept idiomes ${ }^{1}$.

À la diversité des dialectes arabes s'ajoute la diversité des langues des autres peuples ayant fraîchement embrassé l'Islam, notamment les Perses qui ont connu une brillante civilisation enrichie par divers apports culturels —, entre autres grecs depuis l'époque d'Alexandre, et même hindous (on enseignait à Djundisabûr ${ }^{2}$ les sciences hindoues et grecques). C'est ainsi qu'un libre penseur arabo-persan, Ibn al-Muqaffa' (virI ${ }^{\mathrm{e}}$ s. ap. J.-C.), a traduit du persan vers l'arabe les fameuses fables hindoues, donnant au recueil le titre Kalila wa dimna ainsi que shâh-Nâma (Histoire des rois perses).

3) Après une période de flottement et d'hésitation à l'égard de la traduction, limitée par le deuxième Calife Omar ( $\mathrm{VII}^{\mathrm{e}}$ s. ap. J.-C.) aux domaines pratiques (administration), on assiste à des initiatives individuelles, prises par des non-Arabes, rapidement suivies par de vraies politiques de traduction, s'appuyant sur des 'azams (non arabes convertis ou non) parmi lesquels les Califes recrutaient leurs médecins et certains de leurs secrétaires.

Le premier livre traduit au temps des Omeyyades ${ }^{4}$ fut un livre de médecine en langue persane.

4) Mais l'activité de traduction n'a connu un essor remarquable qu'avec la dynastie des Abbasides ${ }^{5}$ à Baghdad soutenue par les Persans, en particulier sous le Califat d'Al

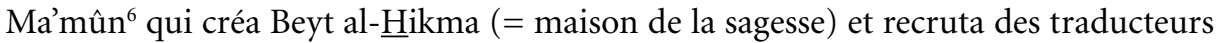
dans les domaines scientifiques et philosophiques. On dit qu'il récompensait le traducteur par le pesant d'or de son livre. De véritables familles de traducteurs ont vu le jour ${ }^{7}$.

La logique grecque fut arabisée à partir du persan puis du syriaque avant d'être traduite directement du grec.

La traduction est devenue ainsi un véritable métier pratiqué individuellement et même en groupe. L'un des plus célèbres traducteurs de l'époque, Hunayn Ibn Ishâq ${ }^{8}$, était surnommé le «maître des traducteurs de l'Islam». Son école domina le $\mathrm{Ix}^{\mathrm{e}} \mathrm{s}$.; on y traduisait surtout du grec.

5) On peut donc dire que la traduction est passée par deux grandes périodes: une période de traduction indirecte, où le persan et le syriaque servaient d'intermédiaires, puis une période où le sanscrit et le grec étaient traduits directement en arabe.

L'intérêt portait essentiellement sur les mathématiques, l'astronomie, la médecine et la philosophie, où Aristote était considéré le premier maître et son commentateur arabe Farâbi, le second maître.

6) Cette tradition arabo-islamique a cependant hérité d'une vieille tradition judéochrétienne. De véritables écoles de traduction existaient déjà. On pourrait en citer l'école nestorienne syriaque de Nizip qui traduisait surtout du grec, l'école Jacobite syriaque kinnisrin et l'école païenne des Sabéens à Harrân (Hellénopolis) ${ }^{9}$. Les liens entre le grec et le syriaque étaient étroits, car l'Église orientale utilisait les deux langues. 
La notion d'école n'était donc pas étrangère à la tradition arabe; c'est son contenu qui a cependant changé. Les écoles arabes n'étaient pas spécialisées dans des langues ou des domaines spécifiques, mais elles se distinguaient par leur approche ou méthode en traduction.

7) Deux écoles se sont illustrées, chacune selon Safadi ${ }^{10}$ issue d'un maître qui l'a imprégnée par sa méthode personnelle:

- La première méthode est celle de Yuhanna Ibn al-Batrîq, Ibn Nấima et autres; elle consiste à considérer le sens de chaque mot grec isolément et à proposer un terme arabe équivalent, et ainsi de suite jusqu'à la fin du texte qu'on veut traduire.

Safadi juge cette méthode médiocre pour deux raisons:

- La première est qu'il n'y a pas en arabe de mots correspondant à tous les mots grecs; il s'en est suivi un recours excessif à l'emprunt au grec.

- La seconde raison concerne les spécificités syntaxiques qui font que les constructions de la phrase, les rapports prédicatifs et les usages métaphoriques ne sont pas identiques d'une langue à l'autre.

- La seconde méthode est celle de Hunayn ibn Ishâq, al Jawhari et autes; elle consiste à prendre la phrase entière, à considérer son sens global puis à la traduire globalement sans tenir compte des mots isolés. Cette méthode est jugée meilleure par Safadi, et c'est ce qui explique selon lui que les traductions de Hunayn ibn Ishââ n'ont pas nécessité de retouches sauf en sciences mathématiques, où il était moins compétent qu'en médecine ou en logique.

8) À la fin du Moyen Âge, la traduction vers l'arabe cessa presque ${ }^{11}$; on assiste à un nouveau phénomène d'une grande portée historique. Les traductions accumulées en arabe et leurs commentaires et les œuvres qui en ont découlé commencèrent à être à leur tour traduits en Europe, d'abord par l'intermédiaire du latin puis dans les idiomes locaux. L'école de Tolède, à titre d'exemple, y joua un rôle très important à partir du XII ${ }^{\mathrm{e}} \mathrm{s}$.

L'essor de l'Europe et son expansionnisme dont le monde arabe a pris conscience avec l'arrivée des troupes de Napoléon Bonaparte en Égypte ont provoqué un choc considéré à juste titre comme le déclic à l'origine des mouvements de renaissance au XIX ${ }^{e}$ s., mouvement dont l'une des plus importantes manifestations fut de nouveau la traduction.

9) Le premier choc ayant été essentiellement militaire (campagne de Bonaparte), l'intérêt se porta en premier lieu sur la traduction mise aux service des armées; les premières écoles modernes furent, en effet, des écoles militaires (telle l'École du Bardo en Tunisie).

Une école des langues vit le jour en Égypte pour former des traducteurs, à partir du français en particulier.

Pendant la seconde moitié du XIX ${ }^{\mathrm{e}}$ s., le Liban connut une activité de traduction intense au service de la presse et de l'enseignement. Dans ce dernier domaine, l'Université anglo-américaine a mis l'accent sur la traduction scientifique et l'Université francophone Saint-Joseph sur la traduction religieuse et littéraire.

Au Liban, une élite de traducteurs bien formés en Occident s'est montrée très active. 
À côté du français et de l'anglais, l'italien a été également pratiqué à cette époque en Méditerrannée à la faveur d'échanges commerciaux actifs avec l'Italie.

Ainsi, la langue arabe, qui avait stagné et régressé sous la domination ottomane, a connu un nouveau développement grâce à la traduction à partir de langues européennes.

À cette époque, une vive polémique a opposé les intellectuels qui, désespérés devant le retard accumulé par l'arabe, ont appelé à promouvoir les parlers au rang de langue officielle à l'instar de l'Europe de la Renaissance et ceux qui, attachés à la dimension sacrée et unificatrice de l'arabe littéral, ont été confortés dans leur position par les effets de la traduction et le regain de vitalité de l'arabe standard.

10) Ce survol rapide du développement de la traduction en arabe donne une idée de la place centrale qu'elle occupait dans le développement de la culture et de la civilisation arabo-islamiques pendant tout le Moyen Âge, mais également dans les contacts et les transferts culturels ainsi que dans la naissance et la renaissance des civilisations. Il n'est qu'à voir le sort réservé au terme qu'utilise l'arabe désignant la traduction pour saisir métalinguistiquement cette dimension:

Le paradigme relatif à la traduction en arabe est dérivé d'une racine quadrilitère fictive [tr3m] extraite d'un vieil emprunt à l'araméen [targmono] qui donna [turzumân] «traducteur» vieilli mais toujours en usage.

C'est cette forme qui a donné les diverses variantes que nous rencontrons dans les textes européens, en particulier les formes Drogman et Dragoman ainsi que le terme français «truchement» qui conserve l'un des sens les plus anciens à savoir «intermédiaire». La survivance de ces vocables témoigne de l'intensité des contacts culturels que la traduction a favorisé dans tous les sens en fonction de l'apport dominant à chaque étape de l'histoire des civilisations en présence.

Au terme de cet aperçu, on pourrait se poser la question: Pourquoi la traduction a-t-elle été un facteur déterminant dans le rayonnement de la civilisation araboislamique puis de la civilisation européenne des Temps Modernes, et pourquoi n'a-telle pas suffi à faire aboutir la renaissance arabe dès le $\mathrm{XIX}^{\mathrm{e}} \mathrm{s}$. ?

Il est évident que, dans les deux premiers cas, il s'agissait de traduire le produit intégral d'une civilisation qui a cessé de se développer par la création continue. Il était donc aisé d'en faire le tour, d'assimiler ce produit et de s'engager dans l'action de dépassement et de création.

Dans le dernier cas, la traduction s'attaque à un produit en extension, qui progresse et se développe à un rythme beaucoup plus rapide que celui de sa traduction. D'autre part, cette action modernisante entamée au début du $\mathrm{XIX}^{\mathrm{e}}$ s., notamment en Égypte, en Syrie, au Liban et en Tunisie, a vu son élan brisé par la colonisation qui a remplacé l'arabe par le français et l'anglais, devenus langues véhiculaires, de culture et d'enseignement. Le besoin et l'effort de traduction ont ainsi perdu de leur acuité initiale.

Les «mouvements de libération nationale» n’ont pas réussi à résoudre cette équation, à assurer un véritable décollage et un développement intégral pour faire sortir les populations arabes de leur sous-développement.

La traduction s'est avérée dans ce cas une condition nécessaire mais non suffisante car elle est un adjuvant pour les civilisations en expansion.

Cependant, la traduction a eu dans tous les cas une fonction de jonction d'une part entre l'Orient et l'Occident et d'autre part entre l'Antiquité et les Temps Modernes. 


\section{NOTES}

1. harf en arabe classique signifie à la fois lettre et idiome.

2. Gondèshâpûre, ville persane que le Sasanide Shapur $1^{\text {er }}$ peupla de prisonniers grecs; elle fut un important centre culturel qui pratiquait l'araméen et qui influença en Islam l'activité intellectuelle et scientifique (notamment en médecine).

3. Considéré comme le premier grand monument littéraire arabe en prose (à l'exception du livre sacré, le Coran).

4. Première dynastie héréditaire en Islam à Damas (661-750 ap. J.-C.)

5. Deuxième dynastie en Islam (750-1259 ap. J.-C.)

6. Septième Calife abbasside (786-833 ap. J.-C.), célèbre par sa culture. Après avoir soumis l'empereur romain d'Orient Michel III, il exigea de lui un exemplaire de tous les livres grecs en sa possession.

7. Citons les Bukhtishûû, famille de médecins de Djundisabûr; les Banû l-Munadjdjim (famille de traducteurs à Baghdad); mais d'autres traducteurs étaient également actifs à Kairouan (Tunisie), et à Cordoue (Espagne).

8. (808-873 ap. J.-C.). Médecin chrétien, le Calife Maümûn le nomma chef des traducteurs. Il traduisit vers l'arabe et le syriaque Platon, Aristote, Discorîdos, Galinos... Son fils Ishâq (911) fut également célèbre. Médecin et philosophe nestorien, il traduisit vers l'arabe des traités de philosophie et de mathématique, ainsi que les traductions syriaques de son père, notamment les Catégories d'Aristote, l'Almageste de Ptolémée et les Éléments d'Euclyde.

9. Au début de l'ère abbasside, elle abrita une importante école de traduction dirigée par le célèbre Thabit ibn Kurra. Les Sabéens y traduisaient des ouvrages grecs de mathématique et d'astronomie; les ouvrages d'astronomie, spécialité de l'école, étaient également hindous, babyloniens et kaldéens.

10. Historien biographe arabe du XIV e s. ap. J.-C.

11. Exceptées les traductions religieuses réalisées du latin vers l'arabe à partir du $\mathrm{XVI}^{\mathrm{e}} \mathrm{s}$. par les chrétiens du Liban.

\section{RÉFÉRENCES}

BADAwI, Abd ar-Rahman (1968) : La transmission de la philosophie grecque au monde arabe, Paris, Vrin.

Berthelot, M. (1893): La chimie arabe au Moyen-âge, Paris, Imprimerie Nationale.

Collectif (1954) : Encyclopédie de l'Islam, Leyde, E. J. Brill. (Série d'articles relatifs aux personnes, aux villes, aux dynasties et aux institutions citées dans le présent article.)

Collectif (1989): Théories de la traduction, éd. par la fondation «Beit al-Hikma», Tunis (en arabe).

Corbin, H. (1964): Histoire de la philosophie islamique, Paris, Gallimard.

Leclerc, L. (1970): Histoire de la médecine arabe, Paris.

MuwÂ̂̂DA, M. (1986) : ㅂarakat attarjama fi Tûnis, "Le mouvement de traduction en Tunisie», Tunis.

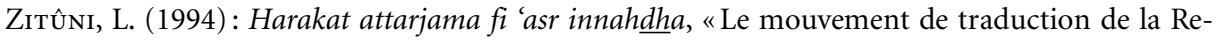
naissance ", Liban. 